\title{
Problems and Pitfalls in ICZM Implementation: Lessons from Some Selected Mediterranean and Black Sea Cases
}

\author{
Stefano Soriani*, Fabrizia Buono and Monica Camuffo \\ Department of Economics, Ca' Foscari University, Venice, Italy
}

\begin{abstract}
Integrated Coastal Zone Management is widely recognised as a set of principles, approaches and tools for the sustainable development of coastal zones. However, while its importance as a theoretical framework for approaching the complexity of coastal governance is not opinable, the problem of translating ICZM principles into every-day management practice still represents a basic point to deal with. This paper aims at clarifying the most important elements that hinder ICZM adoption and implementation. To this purpose, it critically evaluates the results of the EU FP7 Project PEGASO (People for Ecosystem-based Governance in Assessing Sustainable development of Ocean and coast). The project considered ICZM efforts and initiatives in 10 case studies, 7 in the Mediterranean Sea and 3 in the Black Sea. The study confirms that dealing with the multi-scale nature of coastal governance, the poor coordination of policies and administrative fragmentation, the dictatorship of sectoral approaches, the difficulty to promote integration, both thematic and geographic, the complex relationship between voluntary agreements and statutory frameworks, the difficult relationship between science and decision making, and the problem of the sustainability over time of ICZM initiatives and efforts still represent the main factors that hamper a wider adoption of ICZM in the considered cases.
\end{abstract}

Keywords: ICZM implementation; Mediterranean cases; Black Sea cases; EU PEGASO Project

\section{Introduction}

Integrated Coastal Zone Management (ICZM) is regarded as a set of principles and approaches more effective, compared to sectoral perspectives, in addressing the need for sustainability in coastal zones [1-6]. Art. 2 of the Madrid Protocol (2008) defines ICZM as "[...] $a$ dynamic process for the sustainable management and use of coastal zones, taking into account at the same time the fragility of coastal ecosystems and landscapes, the diversity of activities and uses, their interactions, the marine orientation of certain activities and uses and their impact on both the marine and land parts" [7].

Adopted first in USA in late 1960s and early 1970s, ICZM has then evolved through a combination of international programs and initiatives, and research activity that took place in different geographical contexts since the early 1980s. Moreover, the spreading and increasing popularity of the debate on sustainable development has contributed since the early 1990 s to give ICZM the status of one of the most important 'global discourses' regarding resources management in coastal zones $[8,9]$.

Key elements of ICZM are as follows: i) as a dynamic process, ICZM must be based on the acknowledgement of the relationships between ecosystems, socio-economic and political systems; accordingly one of the most important aspects of coastal management is the attempt to integrate approaches, disciplines, tools, and administrative management systems; ii) ICZM has to be tailored on the specific conditions (physical, socio-economic, political, legal and financial) of the considered coastal areas, since it doesn't exist a 'one-size-fits-all' solution for coastal problems; iii) ICZM is a multi-scale process that requires coordination and cooperation between different administrative bodies with competence on different geographical areas; iv) given the complexity of coastal systems and the difficulty to represent it with causality models, adaptive styles of management are required; v) ICZM is a participatory process: this implies that the involvement of all the relevant stakeholders is essential to get results; vi) ICZM strategies and initiatives have to adopt a mix of different instruments (spatial planning, management programs, environmental education and communication, economic instruments); vii) ICZM requires a long-term strategic view of the expected evolution of the framework of coastal and marine uses; again, to this aim public participation is of basic importance, not only to contribute to spread knowledge and to design and implement solutions but also to define the main coastal issues to be addressed by ICZM efforts; viii) ICZM is an iterative process: the results of ICZM strategies and initiatives have therefore to be monitored and assessed periodically.

However, while ICZM can be regarded as a comprehensive theoretical framework aimed at contributing to design new holistic and systemic approaches to coastal governance, the difficulty to translate its principles into practice still remains a critical point. As the European Commission's Demonstration program pointed out, ICZM remains a very difficult process to be managed [10]. More recently, the difficulties that coastal managers very often find in translating ICZM concepts into every-day management practice have been confirmed [11-13].

These difficulties depend on various factors, among which one can recall the huge pressure for coastal development that occurs in many coastal areas, particularly for tourism, energy infrastructure and port activity; conflicts regarding the management of coastal and marine resources; the difficult relation between science, policy and decision making; bureaucratic burdens, lack of coordination and lack of cooperation attitudes; inappropriate planning systems; the difficulty for environmental policy and management to promote integrated perspectives, both thematic and geographic; poor political and financial support to ICZM initiatives and efforts; the complexity

*Corresponding author: Prof. Stefano Soriani, Department of Economics, Ca' Foscari University, Venice, Italy, Tel: +39 041234 9160; E-mail: soriani@unive.it

Received July 20, 2015; Accepted August 20, 2015; Published August 27, 2015

Citation: Soriani S, Buono F, Camuffo M (2015) Problems and Pitfalls in ICZM Implementation: Lessons from Some Selected Mediterranean and Black Sea Cases. J Coast Zone Manag 18: S1-002. doi: 10.4172/2473-3350.1000S1-002

Copyright: ( 2015 Soriani S, et al. This is an open-access article distributed under the terms of the Creative Commons Attribution License, which permits unrestricted use, distribution, and reproduction in any medium, provided the original author and source are credited. 
of participation processes. Moreover, the assessment of the adopted ICZM initiatives still remains a very controversial task, as monitoring and evaluation processes very often concentrate only on procedural and organizational aspects (number of plans/programmes issued, number and kind of public participation exercises organized, level of stakeholder involvement, etc.) rather than on substantial ones (have the ICZM efforts achieved the outcomes they were intended to?) [14-20].

Against this background, this paper considers the problems experienced in ICZM implementation in some Mediterranean and Black Sea coastal areas. It critically evaluates the results of the EU FP7 Project, PEGASO (People for Ecosystem-based Governance in Assessing sustainable development of Ocean and coast, 2010-2014, www.pegasoproject.eu). The main goals of PEGASO were to contribute to bridge the gap between science and decision-making in ICZM, to support national governments and local/regional authorities in the implementation of the Madrid Protocol on ICZM as well as to test and validate a set of tools (indicators, ecosystem accountability, scenarios, participation methods, DSS for coastal management) for the assessment of the main issues affecting the Mediterranean and the Black Sea coastal zones. In order to achieve the aforementioned objectives ten 'Collaborative Application SitEs' (CASEs) were identified in order to represent different scales, coastal issues, expertise and experiences. The consideration and evaluation of the problems reported in the CASEs can contribute to shed light upon the most important difficulties and pitfalls that still hinder the establishment of sustainable ICZM practices. Moreover, the analysis of the work done within these CASEs can also clarify the role that research and cooperation European funded projects can play in supporting ICZM efforts and initiatives.

\section{PEGASO project and ICZM implementation: cases from the Mediterranean and the Black Sea}

The Protocol on Integrated Coastal Zone Management is the seventh Protocol in the Framework of Barcelona Convention (first edited in 1976 and then revised in 1995 and 2004). The Protocol complements the existing set of Protocols of the Convention for the Protection of the Marine Environment and the Coastal Region of the Mediterranean, and represents a milestone in the history of MAP (Mediterranean Action Plan) [7]. It was signed in Madrid in 2008 and entered into force in 2011. As a legally binding instrument of international law, it imposes Mediterranean signatory Countries a further effort to implement ICZM processes, programs and initiatives. As a consequence, it is expected to give a new impulse to the implementation process of integrated management of coastal zones in the Mediterranean Sea. Moreover, even if it represents a binding provision that applies only to Mediterranean Countries, it is expected to contribute to spread ICZM principles and approaches also in the Black Sea. Its application is challenging and requires a wider interaction among policy makers, scientists and stakeholders.

Against this background a basic goal of PEGASO was to facilitate communication, dialogue and networking amongst its various members, which included project partners such as scientific institutions and international organizations and scientists (consortium); project end-users recruited from national and international institutions and organizations (End User Committee) and local stakeholders.

To support this effort 10 CASEs were selected: 7 in the Mediterranean Sea (Al Hoceima, Morocco; Bouches du Rhône, France; North Adriatic, Italy; Cyclades islands, Greece; Dalyan-Köycegiz Special Protected Areas (SPA), Turkey; Nile Delta, Egypt; North Lebanon Coastal zone, Lebanon), and 3 in the Black Sea (Danube Delta,
Romania; Sevastopol Bay, Ukraine; and Guria coastal region, Georgia). Due to the wide geographical distribution and great coastal diversity CASEs were representative of many ecosystems (wetlands and deltas, islands, natural areas, protected areas) of the two basins and their pressure factors. Moreover, the heterogeneity of the considered CASES, particularly with respect to governance processes, policy and legislation frameworks, helped PEGASO partners to try to understand how ICZM principles and approaches can address local specificity.

From the methodological point of view, CASEs teams defined the main issues to be addressed by involving local stakeholders since the very beginning of the project. On the basis of the selected coastal issues, each CASE defined a set of goals to be attained (e.g. to support national and regional authorities in issuing an integrated management plan; to realize an atlas of main coastal and marine uses; to develop a Decision Support System for assessing coastal vulnerability to climate change; to organize visioning exercises; to organize participation exercises with local stakeholders; to assess the progress of ICZM at national level; etc.). During the project a set of tools were developed and made available to CASEs teams (indicators, scenario building, participation methods, economic evaluation tools, etc.); particular attention was paid both to the problem of integrating the different tools, and to build on the results of previous ICZM initiatives, in order to foster knowledge capitalization and to make PEGASO a component of the management process. CASEs reported periodically their results by means of CASEs meetings and virtual forum; PEGASO intranet helped to make comparison among CASEs and to share experiences and lessons learnt.

The EU CASEs have a common framework of EU directives and policies. In the last decade, EU policies were enriched by a more integrated approach to environmental management that interested also coastal zones. Integrated Maritime Policy, the Marine Strategy Framework Directive (2008/56/EC), the Marine Spatial Planning Directive (2014/89/EU), together with the Water Framework Directive (2000/60/EC), the Habitat Directive (92/43/EC), the Flood Directive (2007/60/EC), the Bathing Directive (2006/7/EC), the Reform of the Common Fisheries Policy (1983) and the Recommendation for Integrated Coastal Zone Management (2002/413/EC) provide EU Countries with many instruments to share an integrated coastal zone management and elaborate proper National Strategies. However, despite this common framework EU CASEs have shown quite strong differences, from the good example of France, that since 1986 (Coastal Law, law n. 86-2 of 3 January 1986) formally fulfilled most of the ICZM Protocols articles [9], to the lack of a National Law in Italy or Greece, where coastal zone management is currently developed at local scale and through sectoral policies (tourism, urban development, industry, environmental protection, etc.).

Concerning the Black Sea the common ground is offered by the Convention for the Protection of the Black Sea against Pollution (Bucharest, 1992) and the resulting four Protocols and Strategic Action Plans. This was the result of the growing attention to the intensive anthropogenic pressure exerted since 1960s that altered dramatically the vulnerable system characterized by hypoxic and anoxic water masses permanently existing due to strong vertical stratification. Effects have been recognized on water quality, biological diversity and on all sectors based on marine resources. As a consequence, greater attention has been recently paid by many coastal authorities to sustain ICZM efforts and initiatives.

As mentioned above, 10 CASEs were considered by PEGASO project (Figure 1). The basic information useful to describe these CASEs can be summarised as follows. 
Citation: Soriani S, Buono F, Camuffo M (2015) Problems and Pitfalls in ICZM Implementation: Lessons from Some Selected Mediterranean and Black Sea Cases. J Coast Zone Manag 18: S1-002. doi: 10.4172/2473-3350.1000S1-002

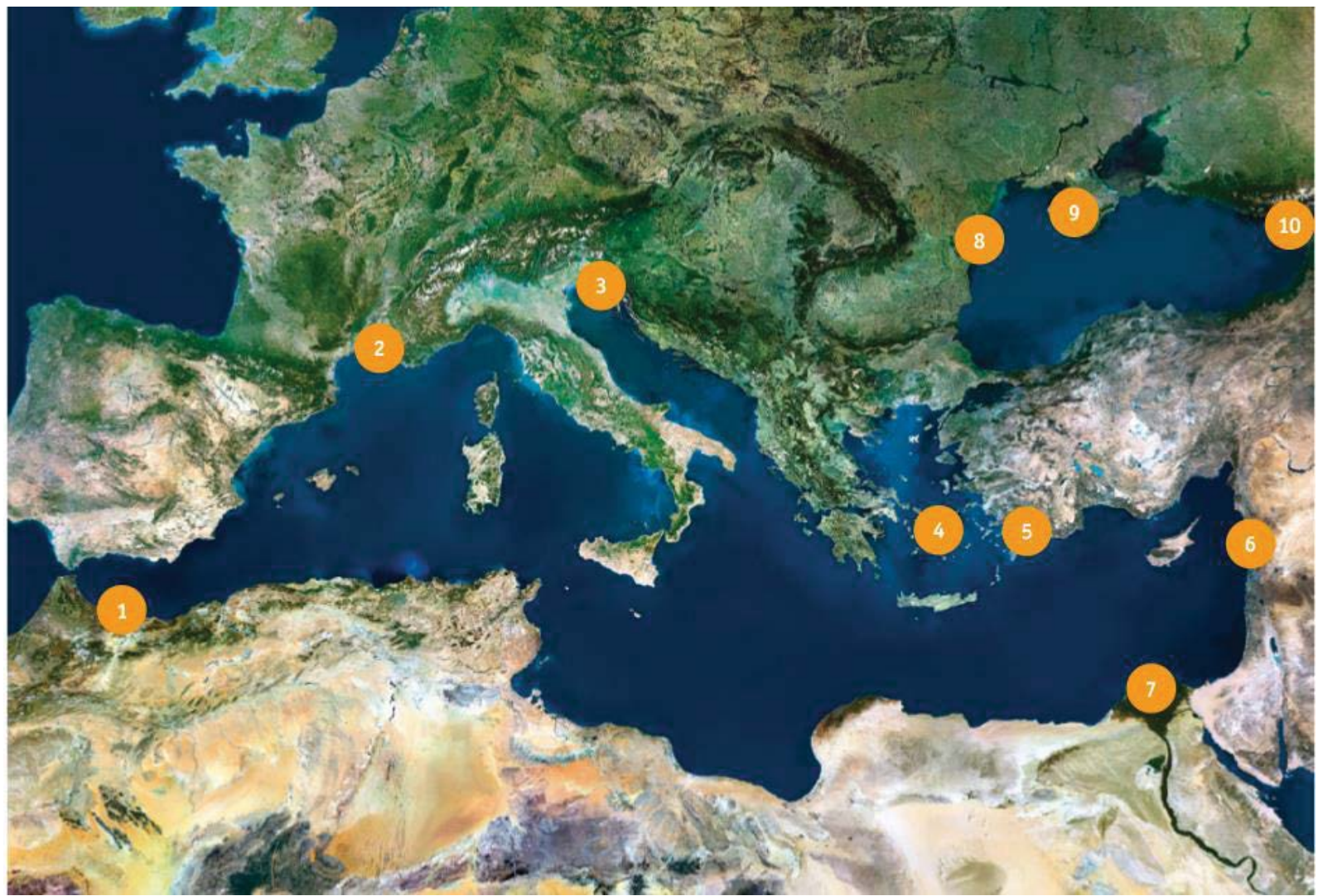

Figure 1: The PEGASO CASEs. 1: Al Hoceima, Morocco. 2: Bouches du Rhône, France. 3: North Adriatic, Italy. 4: Cyclades Archipelago, Greece. 5: KöycegizDalyan, Turkey. 6: North Lebanon Coastal Zone, Lebanon. 7: Nile Delta, Egypt. 8: Danube Delta, Romania. 9: Sevastopol Bay, Ukraine. 10: Guria Coastal Region, Georgia. Source: IUCN (2013) The Pegaso CASEs. Building capacity and sharing experiences for Integrated Coastal Zone Management (ICZM).

\section{Al Hoceima, Morocco}

The low-lying coast of $\mathrm{Al}$ Hoceima has experienced a residential and tourism construction boom on fore dunes or on vulnerable cliffs in recent time. The three major economic activities of the area (fisheries, tourism and agriculture) have compromised the quality of coastal resources. Erosion and degradation of agricultural lands represent the most important problems that coastal managers have to deal with. Moreover, the combination of high population density $(5,310$ inhabitants $/ \mathrm{Km}^{2}$ in $\mathrm{Al}$ Hoceima city) and the exposure to various coastal hazards do not presage a secure future for the coastal population. At national level many ICZM projects have contributed to increase capacity building and awareness on ICZM of local stakeholders, but sectoral approaches still dominate [21]. The CASE aimed at developing and adopting new ICZM tools (territorial diagnosis, the selection and assessment of specific ICZM indicators tailored to the local context, vulnerability assessment) through a participatory approach.

\section{Bouches du Rhône, France}

The coastal zone of the Bouche du Rhône is a fragmented and multifunctional territory, divided in several subsystems (Camargue, Fos, Côte Bleue, Marseille, Calanques), each with its own specific environmental characteristic and issues, zone management schemes, urban area density and industries. Despite this diversity some issues regularly recur such as the contamination of marine waters from land sources, the difficult management of maritime traffic, the over-exploitation of fishery resources, conflicts among coastal uses, as well as the risk of ecosystems degradation due to the project 'Melrose Mediterranean Ltd' for natural gas or oil prospection at sea approximately $30 \mathrm{~km}$ from Marseille [21]. These issues have been so far addressed by a variety of local and regional government organizations including the Water Agency, the Conservatoire du Littoral and the Region PACA (Provence-Alpes-Côte d'Azur). In this context, the work carried out by the PEGASO team in Bouches du Rhône gave a relevant contribution. An environmental and territorial diagnosis was produced to identify the main management issues perceived by local stakeholders, the main pressures on marine environment were defined through the application of an integrated set of local indicators, and a preliminary application of LEAC (Land and Ecosystem Accounting) allowed to partially identify how coastal uses pattern and related conflicts have evolved over the years [22].

\section{North Adriatic, Italy}

The North Adriatic case is situated in the western part of the upper basin of the Adriatic Sea, a sub-regional system of the Mediterranean Sea, linked with it through the Strait of Otranto. The Northern Adriatic is a relatively shallow ecosystem with a depth not exceeding $100 \mathrm{~m}$, with a relevant freshwater input from rivers, responsible both for the high biodiversity and of the pollution and eutrophication of its coastal waters. In spite of the impacts due to human pressures, the Northern Adriatic hosts a very valuable marine biodiversity and ecosystems relevant for their ecological, economic, aesthetic and cultural values. The Italian Northern Adriatic Sea comprises a very precarious coastal environment (sandy beaches and coastal lagoons) naturally subject to 
continuous morphological changes, which are also further threatened by induced erosion and subsidence. Climate change and sea level rise are relevant issues for the case study area considering both the vulnerability of fragile ecosystems such as coastal lagoons, as well as the concentration of cultural and socio-economic values. Moreover despite the environmental value of the North Adriatic coast, the three countries bordering the North Adriatic, namely Italy, Slovenia and Croatia, provide a protection for marine and coastal waters that is less than $0.5 \%$ of the Northern Adriatic Sea [23].

Climate change, water quality, marine protected areas and the coastal areas management policies are therefore all relevant issues for this basin. Against this background, the project has contributed to develop a Decision Support System for climate change risk assessment for the Italian North Adriatic regions, and a forecasting model for the coastal water quality; moreover, it has considered the relation between Marine Protected Areas management and ICZM in the entire North Adriatic basin [21]

\section{Cyclades Archipelago, Greece}

In recent decades, tourism has become the main economic sector in Cyclades islands [21]. The maritime industry plays a basic role in supporting both tourism development and fisheries. Against this background, one of the most important concerns for coastal managers is the management of maritime flows and related environmental impacts. The Greek coastal zone is of particular importance from the economic perspective as well as from the environmental and cultural ones. However, the development and implementation of coastal policy in Greece is still weak. Coastal environment management plans are not effectively implemented, while large number of regulations has not been activated or has been displaced after a short implementation period. The coastal planning system is highly fragmented.

According to this picture, PEGASO project has focused on the development of a DPSIR model using selected indicators and the comparison of the guidelines of ICZM Protocol with the policies related to the emergent coastal issues through a participatory process. Main result was a comprehensive analysis of the state of the coastal zone that shed light on the marginalization that local administrations and stakeholders still suffer in ICZM process.

\section{Köycegiz-Dalyan, Turkey}

Köycegiz-Dalyan is a relatively small Special Protected Area (461.5 $\mathrm{km}^{2}$ ) containing several different environments including a freshwater lake, rivers, a delta with lagoons and wetlands, sandy beaches and sloping hills. The high diversity supports the most productive fishery along the Aegean coast of Turkey. Moreover, the area is one of the most important breeding grounds of loggerhead (caretta caretta) marine turtles in the Mediterranean. It attracts large number of daily visitors from the nearby tourist centres (like Marmaris) in summer months, creating a significant pressure (due to recreational activities and boat traffic) on the ecosystems together with residential development in non-urban areas. Furthermore, the area receives significant amounts of nutrients from natural and anthropogenic sources [21]. Significant impacts are foreseen with climate change. Even if a comprehensive legal framework to address coastal issues has been established since the 1980s the approach is still sectoral. Moreover, the management system for coastal areas is highly centralized with little participation opportunity for local manager and public. The interest on integrated coastal management is grown in the last years but it has not yet real application. In this context, the PEGASO work in Köycegiz-Dalyan
CASE contributed to increase public awareness on the importance of integrated management and to train local coastal managers on relevant tools for ICZM process, namely participation and indicators.

\section{North Lebanon Coastal Zone, Lebanon}

The North Lebanon coastline is $100 \mathrm{Km}$ long, which constitutes around $42 \%$ of the total Lebanese coast. The coast is sandy or pebbly with rocky terraces to protect the coastline from storm surges and erosion due to strong winter storms. The coastal zone is highly affected by urban sprawl and infrastructures development (e.g. the international highway to Syria and the Tripoli Marine Port). Furthermore, many important economic sectors (mining, industries, tourism, fisheries, agriculture) are particularly relevant in the North Lebanon CASE.

Anthropogenic degradation of natural systems, together with the increased intensity and frequency of natural hazards due to climate change are negatively affecting the economy and wellbeing of coastal communities. Despite the recent elaboration of proposals for a National ICZM Strategy, an integrated approach and a coherent use plan for the coastal zone have not been implemented yet. As a consequence, coastal management is still focused on sectoral perspectives. Furthermore, the awareness of the local political system on the importance to adopt more integrated approaches in coastal management, also with respect to climate change, is very low [21]. The North Lebanon CASE gave importance to address coastal artificialization, assessing specific indicators and improving participation, mainly through coastal forum and public participation initiatives.

\section{Nile Delta, Egypt}

The Nile Delta area is about $20,000 \mathrm{~km}^{2}$, from Alexandria in the west to Port Said in the east and covers nearly $240 \mathrm{~km}$ of Mediterranean coastline. Coastal resources are currently degraded because of water pollution, urban sprawl and shoreline erosion, which also negatively affect the agriculture sector in the low-lying areas and fisheries. Several plans have been elaborated in recent times but, due to the lack of institutional coordination and participation together with limited legal framework (National ICZM Strategy was elaborated in 2009 and is still pending of approval), they have not been implemented yet [21].

The approach to coastal management remains mostly Government driven. Against this background, PEGASO aimed at promoting the involvement and collaboration of different organizations and stakeholders. Local coastal forum were organised in order to increase awareness on ICZM process, support the definition of integrated land use plan and improve collaboration among stakeholders. An ICZM plan was developed according to the ICZM Protocol's main principles, the drafted National ICZM Strategy, the specific needs of the area, and the contributions of local stakeholders.

\section{Danube Delta, Romania}

Danube Delta has been involved in many management plans and policies, especially in the second part of the XX century. Such plans drove deep environmental changes, being focused on increasing arable land, urban and industrial development, protection against flow, maintenance of navigation condition and infrastructures. Economic decline and restructuring, which were very severe in the shipyard industry, have added new social and economic problems, particularly relevant for the town of Sulina, located at the mouth of Sulina branch of Danube River [21]. The case shows the importance and complexity of interactions between the different coastal uses, and claims for new integrated approaches in coastal management. However, coastal 
management still suffers from sectoral approaches and administrative fragmentation. To mention is that the area is part of the Danube Delta Biosphere Reserve, but local and national provisions mainly drive its management. In 2003 the National Law for ICZM entered into force, and an Outline ICZM Strategy was developed through a Dutch funded project (MATO/2/RM/9/1/2003-2005). However, these instruments have not been fully implemented, both for the un-coherent institutional framework and for the lack of specific economic incentives. Moreover, the National ICZM Committee, that was in charged with the implementation of the Strategy, appeared inadequate to establish an integrate approach and support local and regional authorities to overcome sectoral perspectives.

Against this background, PEGASO proposed a participatory approach to spatial planning (Sketch Match method) in order to identify problems and opportunities related to ICZM plan formulation. The results of the participatory activities, elaborated by Danube Delta National Institute offer a coherent set of data and information useful for developing a conceptual model of the Sulina socio-environmental system, and for providing decision makers with a clear picture of the most urgent issues to be addressed, and of their relationships.

\section{Sevastopol Bay, Ukraine}

The Bay of Sevastopol provides excellent conditions for ship docking, harbouring, and other maritime activities. The area is also vitally valuable for recreation and housing. Port and port-related activity strongly worsen the quality of ecosystems and of coastal waters, also contributing to the degradation of biological stocks, on which local fishery relies. Another strong pressure derives from the growing population and settlements in Sevastopol (about 400,000 residents, which double in summer time) and untreated sewage waters. The Bay has been regularly investigated and monitored by scientists and research centres since 1997. All the resulting data have been summarized in the form of oceanographic atlases, useful for scientific community but poorly accessible to stakeholders and coastal managers [21]. To answer such need PEGASO local team developed an on-line GIS-based Atlas to describe the current state of Sevastopol Bay environment and interannual trends of the bay's environmental properties. This is expected to promote the debate about the need for issuing a national ICZM Strategy.

\section{Guria Coastal Region, Georgia}

Guria Coastal Region is located along the Black Sea coast of Georgia. The low-lying coast is around $21.5 \mathrm{~km}$ long, from Natanebi River to the southern edge of the city of Poti. Agriculture remains the dominant activity. New tourism infrastructures have been built in recent time. However, the uncoordinated and poorly planned development has limited the access to the beach. An oil terminal is present (Supsa) and a new one will be realised close to Kolkheti National Park, which aims to protect an important wetland. Potential port and oil infrastructure development could strengthen current erosion and water pollution problems. Several ICZM projects were run in Georgia, within the framework of the Bucharest Convention and with international support, but National ICZM strategy and the proposed ICZM Law have not been issued yet. The approach to coastal management is mostly top-down. PEGASO local team dealt with low integration of information and impact assessment through the realization of an Atlas, available also online, and a survey aimed at recording progress in ICZM adoption [21].

\section{Discussion and lessons learnt}

In spite of the different level and experience in the implementation of ICZM practices and initiatives, some common constraints have emerged from the CASEs work. In particular, the following key issues have emerged as basic elements that limit the translation of ICZM principles into management practice.

\section{Bridging science and decision-making}

Despite the wide range of available scientific information related to coastal areas, the communication between science and policy still represents a neglected aspect of ICZM. Against this background, CASEs have underlined the following issues as the main constraints faced in bridging the gap between science and decision-makers: a) the poor involvement of scientists in the management phase of coastal resources; b) the lack of reliable information and data for planning management initiatives; c) and the difficulties related to the communication of scientific findings and their applicability for decision-making. As a point of fact, the CASE of Al Hoceima reported that despite the strong interest shown by decision-makers to scientific and technological tools for addressing coastal issues, the integration of the results in coastal management plans is not guaranteed because the decisions are often made with a top-down approach, without the involvement of university scientists. On the other hand the Köyceğiz-Dalyan SPA reported that the lack of physical, ecological and cultural information hinder effective coastal management. The North Adriatic CASE highlighted that the capability of considering the economical values at stake in the decision process, still remains one of the most critical issues to be addressed in ICZM. It is interesting to note that the CASEs of Sevastopol Bay and Cyclades islands stressed the fact that data on coastal resources is very often not accessible to stakeholders due also to the lack of effective information collection and exchange systems between universities, practitioners and stakeholders.

\section{The need for promoting organizational changes}

The conflicting uses and the plethora of uncoordinated legislation that distinguish coastal zones require the development of new governance models built on partnerships and participatory processes. ICZM seeks to coordinate the different policies affecting coastal zones by promoting integration and cooperation among the different interests and responsibilities of the actors involved. In order to go beyond sectoral policies, a radical change in the existing management practices for coastal areas should occur; in particular for what concern the medium-long term scale perspectives of coastal measures in contrast with the short-term perspectives of political and socio-economic interests and the jurisdictional and natural boundaries of coastal areas. Moreover, our study shows that in general ICZM continues to be not formally acknowledged within the public bodies that have jurisdiction and competences over the coastal zone. Within this context, CASEs remarked how unclear competences management frameworks hinder the coordination of management actions.

For instance, the Aegean Islands CASE reported that on the administrative level, there is no mechanism responsible for the coordination and arbitration of initiatives and actions regarding coastal management. The coastal planning system is fragmented between national, regional and local bodies and it is characterized by many gaps and duplication, resulting in conflicts of jurisdiction in decisionmaking. Furthermore, the existence of strong centralized environmental policies competencies causes dramatic mismatch with the local scale of management (Köyceğiz-Dalyan SPA). To conclude, the experience of CASEs has highlighted that the governance change implied by ICZM is 
still far for being a common reality.

\section{The difficulties involved in the definition of the spatial scale; the multi-scale nature of ICZM as difficult element to deal with}

Environmental governance and the implementation of ICZM in particular, stress on the need of building initiatives based on the specific conditions of the area of interest. However, in the current situation of global change, where several economic, social and environmental impacts are the results of global trends, coastal governance is asked to adopt a multi-scale approach. This means to consider how coastal issues, and the complex relationships between socio-economic and environmental dynamics change according to the different scales involved. This element requires flexibility in management as well as the capability to identify a common vision for the evolution of coastal zones and areas (as well as their mutual relationships). The most important challenge for coastal managers is therefore to design a governance strategy in an uncertain and complex socio-economic and environmental context, in which the problem of scale definition has a fundamental importance. Also for this reason, there is the need of framing ICZM initiatives within strong national and regional strategy and management framework. Against this background, all the CASEs have remarked the need of considering since the planning phase of ICZM initiatives the different organizational, scientific and management scales and at the same time, they have highlighted the difficulties encountered in coordinating this process. In particular, the Bouches du Rhône CASE remarked the need of finding the proper scale not only from a scientific point of view but also from an organizational one. In the North Adriatic CASE, an important challenge is to consider how international coordination and cooperation can contribute to the management of biological resources and quality of coastal and marine waters. It is also important to highlight how the Black Sea Countries call for the adoption of an overarching legal framework on ICZM, in order to address all the initiatives for the management of coastal zones at a more coherent spatial scale.

\section{The issues related to the integrated approach}

Integration is the cornerstone of an ideal ICZM but at the same time, it is one of the trickiest dimensions to achieve and measure. Integration has several dimensions: (1) spatial, (2) temporal, (3) horizontal (among different sectors) and vertical (among levels of government) and (4) among disciplines, which should all be considered in the implementation of ICZM initiatives. During the implementation of their activities CASEs have tried to promote integration in several ways (by involving stakeholders, by integrating different sources of information, by integrating knowledge and point of views on coastal issues, by using different PEGASO tools and promoting interdisciplinary topics). However, the complexity of achieving integration during a short-time project and the difficulty of fostering vertical integration where a top-down approach prevails were widely reported. The CASE of Bouches du Rhône stressed on the fact that integrated management is a very complex process that requires a longterm perspective. In this respect, this CASE shows that efforts should be made at the very beginning of the project to stimulate participation from local stakeholders as well as to create local stakeholder leadership. This will ensure not only the mobilization of the different actors throughout the process but also the continuation after the end of the project. The CASE of Al Hoceima reported the difficulties encountered in attempting to ensure the integration of all the components of coastal management within an effective governance system. For instance, the
CASE reported that most of the problems and conflicts arose in the attempt to promote integration (both during PEGASO project and in previous ICZM efforts) were dependent above all on institutional (poor coordination of sectoral actions, lack of flexibility of administrative and legal procedures, and absence of a shared prospective vision) and legal weaknesses (obsolete texts or unenforced laws, lack of control).

\section{The sustainability of ICZM efforts as one of the main barriers to ICZM implementation}

ICZM process is largely still developed through time-limited projects: this can lead to problem of funding, instability, and lack of commitment from statutory agencies. The risk is for these projects to be considered less relevant than statutory drivers. Therefore, there is a need to enable a follow up of the path and results set during single ICZM projects. CASEs have in many occasions underlined the fact that ICZM initiatives based on short-term projects have little power to involve changes in the governance of coastal resources; moreover, short time initiatives may cause mistrust of stakeholders in participation and ICZM effectiveness. With respect to this point, Al Hoceima CASE reported that a weak point of the several ICZM projects carried out in the region is the lack of consistency and capitalization of knowledge. Moreover, a critical aspect in many ICZM projects is the lack of integration with the structural elements of coastal governance. None of these projects has indeed actually implemented the identified actions. In fact, the challenge of integration and the real capacity of these projects to inspire new approaches to coastal management and therefore inform the decision-making process at national and local scale rarely exceed the declaration of intent.

\section{Conclusion}

ICZM is widely advocated as a systemic and holistic governance approach for dealing more effectively, compared to sectoral perspectives, with coastal issues. Adopted first in USA, ICZM has then evolved through the continuous effort of international organisations and research networks. Today it embraces a set of principles, approaches and tools that together contribute to define one of most important 'global discourses' regarding the issue of sustainability in coastal zones. However, as many technical reports and research surveys confirm, the implementation of ICZM principles remains very problematic and complex.

Our study confirms this point. As we have underlined, the problem of the definition of the proper spatial scale(s) for evaluating coastal issues and possible solutions, poor coordination and administrative fragmentation, the lack of medium and long term political and financial support, the 'dictatorship' of sectoral approaches, the gap between science and decision-making process, the difficult translation of the principle of integration into every-day management practice, and the problem of ensuring the sustainability of ICZM initiatives and efforts, still represent the most important challenges coastal managers and practitioners have to deal with.

In particular, our study underlines the importance of following elements. Firstly, a crucial issue remains the relationship between voluntary initiatives (no-statutory plans and programmes) and statutory provisions (national and local formal regulations, laws, etc.). Undoubtedly, voluntary initiatives and efforts are fundamental for improving coastal governance. This point reflects the fundamental change that occurred to environmental policy and management in the last decades, that is the consideration of private actors, NGOs and local authorities as partners in the process for addressing environmental and 
Citation: Soriani S, Buono F, Camuffo M (2015) Problems and Pitfalls in ICZM Implementation: Lessons from Some Selected Mediterranean and Black Sea Cases. J Coast Zone Manag 18: S1-002. doi: 10.4172/2473-3350.1000S1-002

Page 7 of 7

economic issues, rather than simple recipients of measures decided by national Government with a top-down approach. In this perspective, to develop local leadership, the capability of ICZM supporters and proponents to build coalitions, negotiate and pursue consensus agreements are factors of basic importance for the success of ICZM initiatives and efforts. However, the experiences reported by PEGASO CASEs suggest that changes in the statutory framework, aimed at implementing the strategic principles of sustainable development (for instance, the ecosystem approach) are needed if the efforts have to be maintained over time and influence effectively coastal governance. Statutory approaches remain therefore fundamental to improve coastal governance. Against this background the proposed EU directive on ICZM/MSP (Com (2013)713 final) and the entering into force in 2011 of the Madrid Protocol for the ICZM in the Mediterranean can represent basic steps in this direction.

Linked to the aforementioned point, there is a second fundamental issue: the complex relationship between the local and the national dimensions of ICZM plans and programs. As it is well known, one of the most important elements of ICZM is the recognition that a 'onesize-fits-all' solution does not exist. ICZM is a difficult balance between sustainability principles and the need for meeting local specificity and conditions. In this perspective, our study confirms that, despite the very relevant differences that exist among the institutional frameworks in the considered CASEs, ICZM efforts are very often designed and promoted by local authorities, with the contribution of NGOs and sometimes of the private economic sectors. However, for being effective local efforts and initiatives need to be contextualized within (and endorsed by) a national ICZM strategy. In few words, the national level of government and strategic thinking remain fundamental for the promotion of more integrated and coherent approaches to coastal management. In particular, the national commitment is essential for translating the strategic principles of ICZM into the statutory framework, for contributing to prioritize coastal issues, and for assessing properly the interaction (and tradeoffs) between environmental gains and economic values at stake at different scales. Again, the proposed EU directive on ICZM/MSP and the Madrid Protocol stress the importance of national commitment, in particular when considering the problem of vulnerability to climate change.

Thirdly, our study confirms that an important role in developing and sustaining ICZM initiatives and efforts continues to be played by international organizations' funded research and/or cooperation programmes. This means that ICZM initiatives and efforts remain to a large extent project-time framed, while ICZM needs a mediumlong term perspective to promote sustainability and a more effective coastal governance. The most important problem in this respect is knowledge capitalization. A strategic goal for ICZM projects is to try to avoid that achievement and lessons learnt are being lost once the funding is over. In this perspective, there is an urgent need to design and sustain the activities of governance platforms, capable of spreading knowledge, expertise and field experiences. These should be managed by the organizations that have the development and adoption of ICZM as main institutional commitment.

\section{Acknowledgment}

This research was funded by the FP7 Large scale integrating project PEGASO (People for Ecosystem-based Governance in Assessing Sustainable development of Ocean and coast). Grant agreement n. 244170. We would like to thank the anonymous referees who helped us to improve the manuscript.

\section{References}

1. Sorensen J (1993) The International Proliferation of ICZM Efforts. Ocean
Coastal Management 21: 45-80.

2. Sorensen J (1997) National and International Efforts at ICZM: Definitions, Achievements and Lessons. Coastal Management 25: 3-41.

3. Clayton K, O'Riordan T (1996) Coastal Processes and Management. In O'Riordan T (Ed.), Environmental Science for Environmental Management. London, Longman: 151-164.

4. Olsen S, Tobey J, Kerr M (1997) A Common Framework for Learning from ICM Experience. Ocean Coastal Management 37: 155-174.

5. European Parliament, Council (2002) Recommendation of the European Parliament and of the Council concerning the implementation of Integrated Coastal Zone Management in Europe. Com/2002/413.

6. Haynes R, Potschin M (2011) Integrated Coastal Zone Management and the Ecosystem Approach. PEGASO Deliverable D2.1,CEM Working Papers 7: 11.

7. UNEP/MAP/PAP (2008) Protocol on Integrated Coastal Zone Management in the Mediterranean. Split. Priority Actions Programme.

8. Vallega A (1999) Fundamentals of integrated coastal management. Dordrecht Kluwer Academic Publisher.

9. Billé R, Rochette J (2015) The Mediterranean ICZM Protocol: Paper treaty or wind of change? Ocean Coastal Management 105: 84-91.

10. Burbridge B, Humphrey $S$ (2003) Introduction to the special issue on the European demonstration program on integrated coastal zone management. Coastal Management 31: 121-126.

11. Pickaver AH, Gilbert C, Breton F (2004) An indicator set to measure the progress in the implementation of ICZM in Europe. Ocean Coastal Management 47: 449 462.

12. Forschung and Beratung $\mathrm{GmbH}$ (2006) Evaluation of Integrated Coastal Zone Management in Europe. International Ocean Institute, Final Report. Cologne.

13. Thetis (2011) Analysis of Member States progress reports on ICZM. Venice.

14. Suarez de Vivero JL, Rodriguez Mateos JC (2005) Coastal crisis: the failure of coastal management in the Spanish Mediterranean region. Coastal Management 33: 197-214.

15. Shipman B, Stojanovic T (2007) Facts, Fictions, and Failures of ICZM in Europe. Coastal Management 35: 375-398.

16. McKenna J, Cooper A, O'Hagan AM (2008) Managing by principle: A critical analysis of the European principles of Integrated Coastal Zone Management (ICZM). Marine Policy 32: 941-955.

17. Portman ME, Esteves LS, Le XQ, Khan AA (2012) Improving integration for integrated coastal management: an eight country study. Science of the Total Environment 439: 194-201

18. Alves FL, Sousa LP, Almodovar M, Phillips MR (2013) Integrated Coastal Zone Management (ICZM): a review of progress in Portuguese implementation. Regional Environmental Change 13: 1031-1042.

19. Buono F, Soriani S, Camuffo M, Tonino M, Bordin A (2015) The difficult road to Integrated Coastal Zone Management in Italy : Evidences from the Italian North Adriatic Regions. Ocean Coastal Management 114: 21-31.

20. Soriani S, Buono F, Tonino M, Camuffo M (2015) Participation in ICZM initiatives: Critical aspects and lessons learnt from the Mediterranean and Black Sea experiences. Marine Pollution Bulletin 92: 143-148.

\section{Pegaso (2015) D5.1A CASES reporting}

22. Ivanov E, Nowell M, Morisseau F (2012) LEAC methodology for coast and marine accounts. With contributions from Françoise Breton. CEM Working Paper 10_Version.2.0: 31.

23. Camuffo M, Soriani S, Zanetto G (2011) The evolution of marine protected areas (MPAs): the North Adriatic case. Management of Environmental Quality: An International Journal 22: 59-71.

This article was originally published in a special issue, entitled: "Integrated Coastal Zone Management", Edited by Javier Garcia Sanabria, University of Cadiz, Spain 